\title{
New Tumor Event Information
}

National Cancer Institute

\section{Source}

National Cancer Institute. New Tumor Event Information. NCI Thesaurus. Code C156810.

Data pertinent to a newly discovered tumor. 